\title{
SYMPOSIUM PROCEEDINGS
}

\section{PROCEEDINGS FROM THE 11TH ANNUAL UNIVERSITY OF CALGARY LEADERS IN MEDICINE RESEARCH SYMPOSIUM}

VOL 44 NO 1 MARCH 2021

\author{
Courtney L. Schubert, MSc, Jessica Tjong, MSc, Benjamin W. Ewanchuk, PhD, Robert T. Moore, BSc, Morley \\ D. Hollenberg, DPhil, MD, Doreen M. Rabi, MD, MSc \\ Cumming School of Medicine, University of Calgary, Alberta, Canada \\ Clin Invest Med 2021;44(1):E42-57; DOI: 10.25011/cim.v44i1.35079
}

\begin{abstract}
On November 8th, 2019, the Cumming School of Medicine at the University of Calgary hosted the 11th annual Leaders in Medicine (LIM) Research Symposium. Dr. Donald A. Redelmeier, Professor at the University of Toronto and Canada Research Chair in Medical Decision Sciences, served as the keynote speaker with a talk entitled "Pitfalls of Reasoning and Clinical Medicine". In addition, there were five oral and 64 poster presentations. These presentations covered topics ranging from health promotion to neuroimaging. The event celebrated the continuing success and diversity of the LIM program and the training of clinician-scientists at the University of Calgary.
\end{abstract}

Correspondence to: Doreen Rabi Email: drabi@ucalgary.ca

\section{INTRODUCTION}

Clinician-scientists play a crucial role in the advancement of clinical research. As physicians with formal research training, they are well positioned to investigate clinically relevant research questions leading to the translation into clinical practice. Since 1997, the Leaders in Medicine (LIM) program has provided University of Calgary students with the opportunity to pursue post-graduate education alongside their medical training. Through the LIM program, students complete their MD education in combination with a PhD, MSc, MA, MBA or JD. The LIM program has grown to more than 100 full and affiliate members and is one of the largest clinician-investigator training programs in Canada. Through a variety of mentorship and professional development events, the LIM program prepares students with a diverse set of skills so that they may excel in both their academic and clinical careers.

The program's strength lies in that LIM activities are both highly strategic and student-led. Professional development opportunities, such as the LIM research symposium, are planned and implemented by students, and are designed to elevate the profile of student work, create networking opportunities and provide opportunities for scientific communication skill development. The 11th Annual LIM Symposium was held on November 8th, 2019 at the University of Calgary. The day-long event opened with welcoming remarks from Dr. Jon Meddings, Dean of the Cumming School of Medicine, and Dr. Christopher Naugler, Associate Dean of the Undergraduate Medical Program. Dr. Doreen Rabi, LIM Director, then took centre stage to discuss the incredible strides that the LIM program has made over the past year.

The annual LIM Symposium is a true celebration of the LIM program, serving to promote the diversity of research within the program and to highlight the accomplishments of our students in both the LIM community and the University of Calgary as a whole. In total, the 2019 event included five oral and 64 poster presentations, and over 150 registered attendees and guests. The poster presentations (Figure 1) were divided into and judged in ten different categories, ranging from health promotion to neuroimaging, exhibiting the breadth of research being conducted at the University of Calgary. These poster sessions allowed students to share their research with faculty, alumni, and fellow students within the LIM community. Additionally, the two poster sessions encouraged networking between students, alumni, and faculty as only half the students presented their posters during each session (Figure 2). We were honored to have three LIM Alumni in attendance participating as judges: Dr. Mark Gillrie, Dr. Mary Dunbar, and Dr. Michelle Buresi. We are also grateful to the other 30+ faculty and post-doctoral fellow poster judges who volunteered their time to contribute to and enrich the experience of every student during the symposium. 
FIGURE 1.

POSTER SESSION AT THE 11TH ANNUAL LIM SYMPOSIUM, WAS HELD IN THE ATRIUM OF THE HEALTH RESEARCH AND INNOVATION CENTRE AT THE UNIVERSITY OF CALGARY.

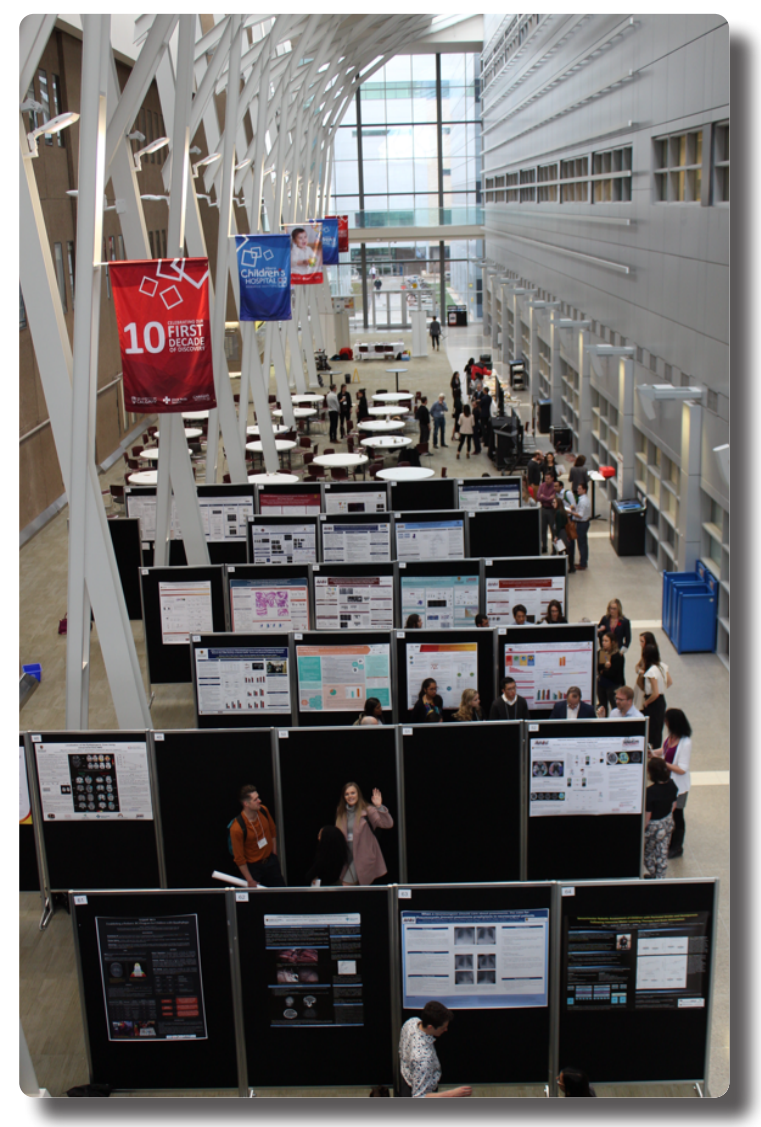

Dr. Donald Redelmeier was the 2019 LIM Symposium keynote speaker. Dr. Redelmeier is the Canada Research Chair in Medical Decision Sciences, Professor at the University of Toronto, Director of Evaluative Clinical Sciences at Sunnybrook Health Sciences Centre, Staff Physician in the Division of General Internal Medicine at Sunnybrook Health Sciences Centre and a Senior Scientist at the Institute for Clinical Evaluative Studies in Ontario. He is active in clinical care for patients with multiple medical illnesses. Dr. Redelmeier's talk, entitled "Pitfalls of Reasoning and Clinical Medicine", featured a unique clinical case, the roles of medical decision sciences throughout the management of the clinical case, and clinical pearls for medical students as physicians in training.

The student oral presentations were extremely well-received, with high quality research presented from a variety of fields. The student oral presenters were Nicole Burma, Asha Hollis, Daniel J. Meyers, Sarthak Sinha and Daniela Urrego. Nicole Burma's talk was awarded Best Oral Presentation (Figure 3). These presentations are summarized on the following pages.
This year's symposium also introduced a new mentorship panel component. Three staff physicians from various clinical and research backgrounds participated in the inaugural Q\&A style panel that addressed student questions on research in medicine, medical training and physician jobs for the future. The three physicians on the panel were Dr. Lara Cooke, LIM alumnus Dr. Braedon McDonald and Dr. H. Tom Stelfox.

The symposium closed with the presentation of awards. The following students won the award for the best poster presentation in their respective category: Danielle C. Lynch for Big Data, Alice L. Yuan for Cancer Biology, David G. Guzzardi for Cell Biology, Courtney L. Schubert for Health Promotion, Benjamin W. Ewanchuk for Immunology and Infection, Amanda M. Henderson for Internal Medicine, Srishti Shrivastav for Medical Education, Dennis Dimond for Neuroimaging, Max A. Hamilton for Neurosciences, and Cynthia K. Kahl for Neurotechnology (Figure 3). The LIM Mentorship award for 2019 was presented to Dr. Jane Shearer. The inaugural Cochrane Award, which is awarded to a student who has demonstrated excellence in academic productivity while in the undergraduate medical program, was presented to LIM student, Andrea Kuczynski. The Student Co-Chair Award was presented to LIM student, Laura Palmer, for her work as Chair of the LIM Program for the past two years. Finally, Dr. Morley Hollenberg provided closing remarks, celebrating the high level of research that was presented during the symposium and emphasizing the importance of pursuing research during medical training.

We would like to acknowledge the following faculty members who volunteered their time to judge the oral presentations: Dr. Christopher Anderson; Dr. Donna-Marie McCafferty; Dr. Doreen Rabi; and Dr. Donald Redelmeier. Additionally, the symposium would not have been possible without the support of the LIM Student Executive and the countless student volunteers throughout the LIM community (Figure 4).

Finally, we would like to thank and acknowledge the generous support from departments and institutes at the University of Calgary: Cumming School of Medicine; Department of Medicine; Department of Clinical Neuroscience; Undergraduate Medical Education Program; Alberta Children's Hospital Research Institute; Cumming School of Medicine Alumni Office; Department of Physiology and Pharmacology; Libin Cardiovascular Institute; Snyder Institute for Chronic Diseases; Hotchkiss Brain Institute; McCaig Institute for Bone and Joint Health, O'Brien Institute for Public Health (IPH); Department of Microbiology, Immunology \& Infectious Disease; Department of Surgery; Graduate Education Program in Community Health Sciences (MDCH); Medical Science Graduate Program; Department of Psychiatry; and Charbonneau Cancer Institute. 
FIGURE 2.

LEADERS IN MEDICINE AFFILIATE STUDENT, MICHAEL JI, SHARED HIS RESEARCH DURING THE STUDENT POSTER PRESENTATIONS.

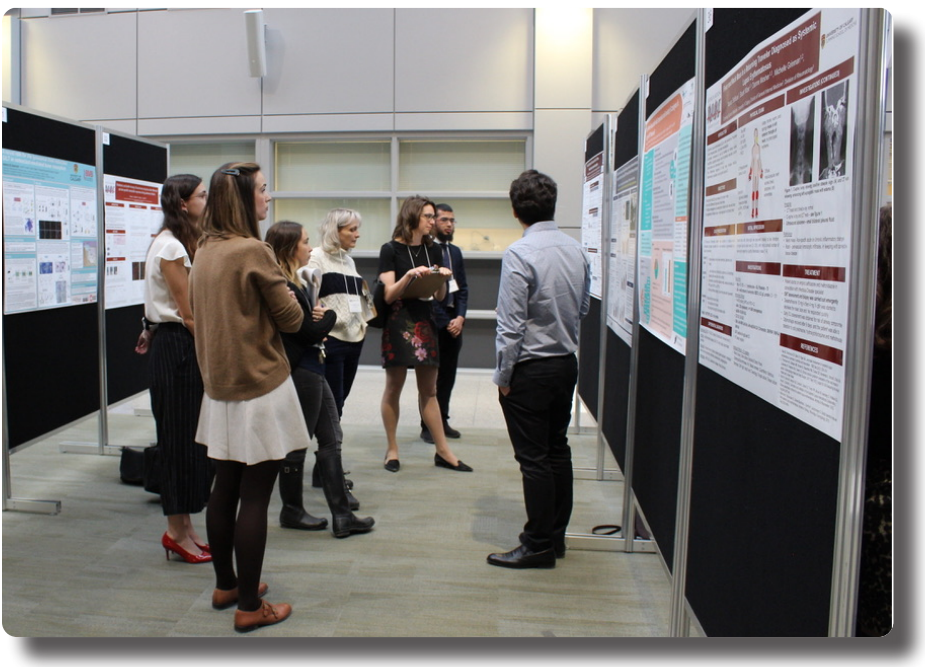

FIGURE 3.

BEST ORAL PRESENTATION AND BEST POSTER PRESENTATION AWARD WINNERS.

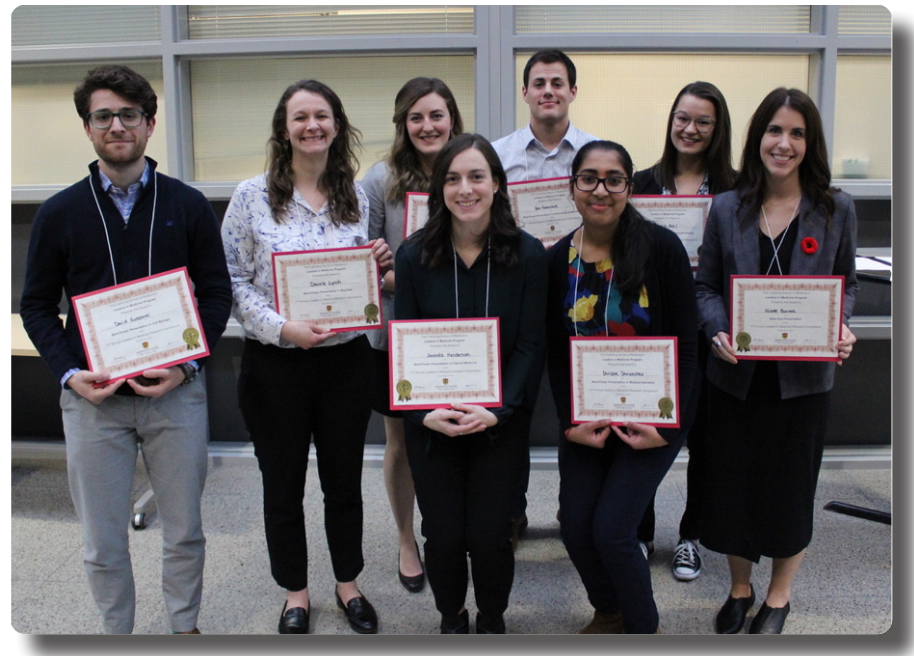

FIGURE 4.

DIRECTORS AND STUDENT EXECUTIVE OF THE UNIVERSITY OF CALGARY LIM PROGRAM.

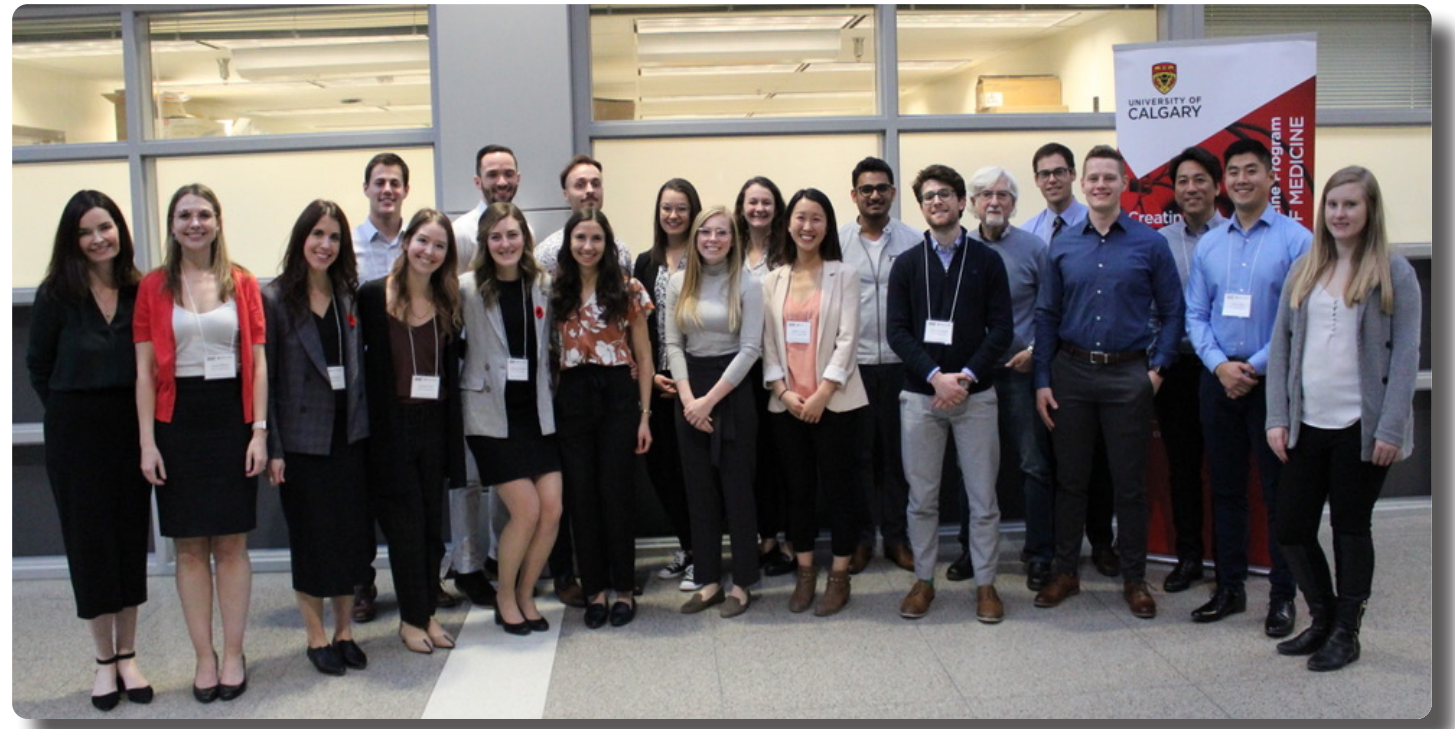




\section{ORAL PRESENTATIONS}

The following are titles and authors of abstracts selected for oral presentation.

Name underlined indicates the presenter.

\section{MICROGLIAL PANNEXIN-1 UNDERLIES CONDITIONED PLACE AVERSION TO MORPHINE WITHDRAWAL}

Nicole E. Burma ${ }^{1,2}$, Charlie H.T. Kwok ${ }^{1,2}$, Tuan Trang ${ }^{1,2}$

'Department of Comparative Biology \& Experimental Medicine, ${ }^{2}$ Department of Physiology \& Pharmacology, Hotchkiss Brain Institute, University of Calgary, Calgary, $\mathrm{AB}$

\section{PEDIATRIC TRANSCRANIAL STATIC MAGNETIC FIELD STIMULATION MODULATES MOTOR LEARNING}

Asha Hollis', Ephrem Zewdie'2, Alberto Nettel-Aguirre², Alicia Hilderley³, Hsing-Ching (Cherie) Kuo², Helen L Carlson $^{2}$, Adam Kirton ${ }^{2}$

${ }^{1}$ Cumming School of Medicine, 2Department of Pediatrics, Cumming School of Medicine, ${ }^{3}$ Hotchkiss Brain Institute, Cumming School of Medicine, University of Calgary, Calgary, AB

THE LUNG IMMUNE PROGNOSTIC INDEX DISCRIMINATES SURVIVAL OUTCOMES IN PATIENTS WITH SOLID TUMORS TREATED WITH IMMUNE CHECKPOINT INHIBITORS

Daniel E. Meyers ${ }^{1 *}$, Igor Stukalin ${ }^{1 *}$, Isabelle A. Vallerand ${ }^{2}$, Ryan T. Lewinson ${ }^{2,3}$, Aleksi Suo', Michelle Dean', Tina Cheng', Daniel Y.C. Heng1, D. Gwynn Bebb'1, Don G. Morris1

'Department of Oncology, 2 Division of Dermatology, ${ }^{3}$ Faculty of Kinesiology, University of Calgary, Calgary, AB. "These authors contributed equally to this work.

\section{MOLECULAR DISSECTION OF SKIN REGENERATION}

AND SCARRING USING SINGLE-CELL SEQUENCING: IMPLICATIONS FOR PRECISION MEDICINE

Sarthak Sinha', Elodie Labit', Sepideh Abbasi1, Nilesh Sharma', Arzina Jaffer', Prajay Shah1, Jo Stratton1, Jeff Biernaskie $^{1-3}$

${ }^{1}$ Comparative Biology and Experimental Medicine, Faculty of Veterinary Medicine, ${ }^{2}$ Alberta Children's Hospital Research Institute, ${ }^{3}$ Hotchkiss Brain Institute, Cumming School of Medicine, University of Calgary, Calgary, AB

LOSS OF REGULATOR OF G-PROTEIN SIGNALLING 2 (RGS2) IN THE MOUSE UTERUS RESULTS IN INCREASED UTERINE CONTRACTILITY-IMPLICATIONS FOR QUIESCENCE IN HUMAN PREGNANCY

Daniela Urrego ${ }^{1-3}$, Stephen Wood $^{2}$, William C Cole', Robert
Newton ${ }^{3}$, Donna M Slater ${ }^{1-3}$

${ }^{1}$ Alberta Children's Hospital Research Institute, ${ }^{2}$ Department of Physiology and Pharmacology, ${ }^{3}$ Department of Obstetrics and Gynaecology, ${ }^{4}$ Department of Cell Biology and Anatomy, University of Calgary, Calgary, $A B$

\section{POSTER ABSTRACTS}

Name underlined indicates the poster presenter.

HOSPICE PHYSICIAN'S EXPERIENCES WITH PATIENT REQUESTS FOR MEDICAL ASSISTANCE IN DYING IN A CANADIAN CONTEXT

Srishti Shrivastav', Amy Tan ${ }^{2}$

${ }^{1}$ Department of Kinesiology, University of Calgary, ${ }^{2}$ Department of Family Medicine, University of Calgary, Calgary, AB

Introduction: In June 2016, Medical Assistance in Dying (MAiD) was legalized in Canada for terminally-ill patients. Given the new landscape that Canadian physicians are now navigating with the current MAiD legislation, it is important to explore and determine how the new legislation has both been navigated by physicians and affected physicians, personally and professionally. The study explores the "lived experiences" of physicians who routinely practice in the realm of end-of-life/hospice care in Canada and describe how the implementation of MAiD has impacted their daily work and practice.

Methods: Five hospice physicians from the Calgary Zone in Canada completed in-depth, semi-structured interviews. An interpretive phenomenology analysis approach was used. Data analysis was concurrent with data collection using an iterative analysis approach completed using inductive thematic analysis. Both researchers coded interview audio tapes/ transcripts separately and discussed the emerging themes to form the framework. Atlas.ti was used to code and manage the data.

Results: Eight major themes emerged: 1) navigating MAiD at the Government and Health Care System; 2) navigating the logistics of MAiD provision within the hospice; 3) how MAiD impacted the patient-physician interactions/relationship; 4) balancing capacity for MAiD with palliative care; 5) impact of MAiD provision in hospices on team dynamics; 6) navigating hospice physician's personal values surrounding MAiD; 7) supporting resources used to navigate MAiD; and 8) areas of support requested for MAiD.

Conclusion: The transition that hospice physicians in Calgary had to navigate with regards to the legalization of MAiD in Canada had to be processed on multiple levels. 
RISK FOR TYPE 2 DIABETES AND CARDIOVASCULAR HEALTH IN CHILDREN TREATED WITH SECOND-GENERATION ANTIPSYCHOTICS

Amanda M. Henderson'1, Nazrul Islam², George G. Sandor ${ }^{3}$, Constadina Panagiotopoulos ${ }^{3}$, Angela M. Devlin ${ }^{3}$

${ }^{1}$ Cumming School of Medicine, Faculty of Medicine, University of Calgary, Calgary, $\mathrm{AB},{ }^{2} \mathrm{MRC}$ Epidemiology Unit, University of Cambridge, Cambridge, UK, ${ }^{3}$ Department of Pediatrics, University of British Columbia, BC Children's Hospital Research Institute, Vancouver, BC

Introduction: Second-generation antipsychotics (SGAs) are used to treat mental health conditions in children, but have side effects including weight gain, dyslipidemia, hypertension, and risk for type 2 diabetes. These side effects are well-known risk factors for cardiovascular disease. However, little is known about the cardiovascular health of SGA-treated children.

Methods: This was a cross-sectional study of children (aged 6-18 years) with mental illness who were SGA-treated $(n=47)$ or SGA-naive $(n=37)$ and control children ( $n=83$, no mental illness). Anthropometrics and fasting bloodwork were collected. Cardiovascular health was assessed by two measures: central pulse-wave velocity (PWV) was measured by standard M-mode echocardiography with Doppler tracing (indicator of arterial stiffness); and carotid intima-media thickness (cIMT) was measured (subclinical indicator for atherosclerosis).

Results: SGA-treated children had greater BMI z-scores $(p<0.001)$ and higher $(p<0.001)$ prevalence of overweight/ obesity (BMI $\geq 85$ th percentile for age and sex) than SGA-naive and control children. SGA-treated children had higher fasting plasma insulin $(p=0.016)$ and $21.7 \%$ had hyperinsulinemia (fasting insulin $\geq 100 \mathrm{pmol} / \mathrm{L}$ ) compared with $12.9 \%$ of SGA-naive children. No differences in fasting glucose or circulating lipids were observed. Hypertension was observed in $14.9 \%$ of SGA-treated children, compared to $5.4 \%$ of SGA-naive and $6.0 \%$ of control children. SGA-treated $(p=0.002)$ and SGA-naive children $(p<0.001)$ had higher PWV than controls (adjusted for age, sex, BMI, systolic blood pressure). No effect of SGAs or mental health diagnosis on cIMT was observed.

Conclusion: Children with mental illness have greater arterial stiffness than controls. Future studies are warranted to delineate the mechanisms underlying the effects of SGAs and mental illness on cardiometabolic health in children.

BRONCHOALVEOLAR LAVAGE FLUID LYMPHOCYTOSIS IN CHRONIC HYPERSENSITIVITY PNEUMONITIS: SYSTEMATIC REVIEW AND META-ANALYSIS

Nicola Adderley ${ }^{1}$, Christopher Humphreys², Hayley Barnes $^{3}$, Brett Ley ${ }^{4}$, Zahra A. Premji ${ }^{5}$, Kerri A. Johannson ${ }^{2,6}$
${ }^{1}$ Faculty of Medicine \& ${ }^{2}$ Department of Medicine, University of Calgary, Calgary AB, ${ }^{3}$ Department of Allergy, Immunology and Respiratory Medicine, Alfred Hospital, Melbourne, Australia, ${ }^{4}$ Department of Medicine, University of California, San Francisco, CA, USA, Departments of ${ }^{5}$ Libraries and Cultural Resources and ${ }^{6}$ Community Health Sciences, University of Calgary, Calgary, AB

Introduction: Chronic hypersensitivity pneumonitis (CHP) shares clinical and radiological features with other interstitial lung diseases (ILD). The utility of bronchoalveolar lavage (BAL) fluid analysis in the diagnosis of CHP remains unclear. The objectives of this systematic review and meta-analysis are to describe the characteristics of BAL fluid analysis in CHP and determine the performance characteristics of BAL lymphocyte counts to differentiate CHP from non-CHP ILD.

Methods: We systematically searched electronic databases and identified studies, which were synthesized, including meta-analyses to estimate pooled lymphocyte estimates, following Meta-analysis of Observational Studies in Epidemiology guidelines. Using individual patient data (IPD) from studies comparing CHP and nonCHP ILD, we tested the performance characteristics of BAL lymphocytosis at thresholds of $>20 \%,>30 \%,>40 \%$ and $>50 \%$.

Results: Our search yielded 2,500 articles, of which 38 were included in the meta-analysis. The overall pooled estimate for lymphocytosis in CHP was $41.9 \%$ [Cl 37.046.8] vs $9.6 \%$ [Cl 6.1-13.1] in idiopathic pulmonary fibrosis, 23.1\% [Cl 16.2-30.1] in connective tissue disease ILD, and $13.7 \%$ [Cl 7.6-19.9] in sarcoidosis. There was significant heterogeneity in lymphocyte counts from patients with CHP (I2=95.4\%). IPD from eight studies yielded a pooled cohort of 716 patients. Lymphocytosis at a cut-point of $20 \%$ demonstrated the greatest sensitivity $[0.68, \mathrm{Cl} 0.61-$ $0.75]$, while specificity was maximized at a cut-point of $>50 \%$ [0.92, Cl 0.90-0.94].

Conclusion: Patients with CHP have a higher BAL fluid lymphocytosis \% compared with non-CHP ILD. Applying higher thresholds of lymphocytosis improves specificity at the expense of sensitivity. Parent studies are limited by incorporation bias.

\section{SUBJECTIVE COGNITIVE DECLINE AND MILD BEHAVIORAL IMPAIRMENT TOGETHER PREDICT INCIDENT COGNITIVE DECLINE AT 3 YEARS BETTER THAN EITHER SYNDROME ALONE}

Sophie Hu${ }^{1,5,7,8}$, Sascha Gill5,8, Eric Smith ${ }^{2,5,8}$, Nils Forkert ${ }^{3,5,8}$, and Zahinoor Ismail ${ }^{1,2,4-8}$

${ }^{1}$ Department of Community Health Sciences, ${ }^{2}$ Department of Clinical Neurosciences, ${ }^{3}$ Department of Radiology, ${ }^{4}$ Department of Psychiatry, ${ }^{5}$ Hotchkiss Brain Institute, 
${ }^{6} \mathrm{O}^{\prime}$ Brien Institute for Public Health, ${ }^{7}$ Mathison Centre for Mental Health Research, ${ }^{8}$ Ron and Rene Ward Centre for Healthy Brain Aging Research, University of Calgary, Calgary, $A B$

Introduction: Subjective cognitive decline (SCD) refers to a perceived decline in cognition. SCD is associated with increased risk of dementia and may be associated with psychiatric symptoms including depression and anxiety. Mild behavioral impairment (MBI) is a validated neurobehavioral syndrome characterized by later-life emergence of sustained neuropsychiatric symptoms as an at-risk state for incident cognitive decline. There are currently no comparative studies of SCD and/or MBI that determine the odds of incident cognitive decline.

Methods: Participants were volunteers at Alzheimer's Disease Centers, with a baseline Clinical Dementia Rating Scale (CDR) of 0 (i.e., cognitively unimpaired). Outcome was a change to $C D R>0$ at three years. SCD and $\mathrm{MBI}$ status were derived at baseline. Odds ratios for cognitive decline at three years were calculated for $\mathrm{MBI}-$ SCD-, MBI-SCD+, MBI+SCD-, and MBI+SCD+ using logistic regression modelling. Patients with psychiatric conditions were excluded.

Results: Data was analyzed for 2,769 participants (median age $=73,63 \%$ females). Of these, 1,536 were MBI-SCD-, $254 \mathrm{MBI}-\mathrm{SCD}+, 743 \mathrm{MBI}+\mathrm{SCD}-$, and $236 \mathrm{MBI}+\mathrm{SCD}+$. ORs for incident cognitive decline at three years were 3.61 [2.425.38] for MBI-SCD+, 4.76 [3.57-6.34] for MBI+SCD-, and 8.15 [5.71-11.64] for $\mathrm{MBI}+\mathrm{SCD}+(p<0.0001)$. Age, sex and education neither modified nor confounded.

Conclusion: $\mathrm{MBI}$ alone had greater odds of cognitive decline than SCD alone, but $M B I+S C D+$ together had the greatest odds of cognitive decline $(O R=8.15)$ consisting of $\sim 10 \%$ of the sample. SCD and MBI could be an inexpensive and efficient method to select those at higher odds for cognitive decline for referral to dementia prevention programs.

OPTIMIZING THE PHYSICAL AND SOCIAL ENVIRONMENT WITHIN HOSPITALS TO IMPROVE CARE FOR HOSPITALIZED PATIENTS WITH DEMENTIA: A SYSTEMATIC REVIEW

Caitlan Reich', Hannah Lyons², Jayna Holroyd-Leduc ${ }^{1}$

${ }^{1}$ Cumming School of Medicine, University of Calgary, Calgary, $A B,{ }^{2} Q u e e n ' s$ University, Kingston, ON

Introduction: As the population ages, the number of individuals living with dementia is increasing. This has implications for the healthcare system, as those with dementia are hospitalized more frequently and for longer periods. Acute care environments present specific challenges to those with dementia; however, the interplay between physical and social environmental design and dementia symptoms and behavior remains unknown. Our aim is to systematically review studies that modified the physical and/or social environment in acute care in order to improve care for hospitalized older adults with dementia.

Methods: All experimental/quasi-experimental studies involving an intervention and a comparison group that modified the environment (physical and/or social) within acute care with the aim of improving care provided to patients with dementia/cognitive impairment were of interest. We searched MEDLINE, Embase and CINAHL through to June 2019 and retrieved published English-language articles meeting inclusion criteria. Risk of bias was assessed using GRADE. This study is registered with PROSPERO.

Results: Following the database search, 10,926 citations were retrieved, with 9,688 remaining after removal of duplicates. PRISMA guidelines were followed. After title and abstract screening, 317 full texts were assessed for eligibility. 43 full texts met inclusion criteria. Data abstraction and qualitative summary of findings is currently underway. Quantitative analysis (meta-analysis) will be considered if there are appropriate studies to conduct such an analysis.

\section{RECOMMENDATIONS FOR CANNABIS USE IN PREGNANCY AMONG SOURCES OF CANNABIS SALES IN ALBERTA}

Mirna Matta', Emily Mostofi', Kathleen Helen Chaput ${ }^{2}$

${ }^{1}$ Cumming School of Medicine, ${ }^{2}$ Department of Obstetrics and Gynaecology, University of Calgary, Calgary, AB

Introduction: Since the legalization of cannabis in Canada, there is increasing awareness in the medical community of the need for high quality evidence of its effects, particularly during pregnancy. Cannabis is the most commonly used drug in pregnancy, with approximately $2.5 \%$ of pregnant women in Canada reporting use to their physicians yearly. An increase in cannabis use is anticipated post-legalization. Many pregnant women report using cannabis for morning sickness, despite evidence that it increases risks of preterm birth and maternal pregnancy complications, and may be linked with abnormal infant brain development. Consequently, it is recommended that pregnant women abstain from cannabis use. We sought to explore whether Alberta cannabis dispensaries are sharing the recommendations that pregnant women abstain from use.

Methods: In our preliminary study, we visited five dispensaries in Calgary, $A B$ and online, including the provincial government website responsible for regulating the sale of cannabis, to measure the proportion that provided warnings and/or information about cannabis use in pregnancy. 
Results: $60 \%$ of the dispensaries, and $15 \%$ of the websites visited provided no explicit information or advisory to abstain from use during pregnancy, including the provincial government website. $40 \%$ of dispensaries recommended a "start low and go slow" protocol, despite the request for information for a pregnant customer.

Conclusion: Posted warnings advising abstinence from cannabis use during pregnancy in Alberta dispensaries, on websites, and on cannabis products could increase awareness of the maternal and fetal risks associated with cannabis consumption in pregnancy and potentially mitigate negative perinatal health outcomes.

\section{POPULATION ESTIMATES OF DRIVING UNDER THE INFLUENCE OF MARIJUANA IN THE ERAS OF PRE- AND POST-LEGALIZATION}

Laura Rivera', Scott Patten ${ }^{2,3}$

${ }^{1}$ Undergraduate Medical Education, ${ }^{2}$ Department of Psychiatry, ${ }^{3}$ Department of Community Health Sciences, University of Calgary, Calgary, $A B$

Introduction: Recreational use of cannabis was legalized in Canada in 2018. This work characterized the prevalence of driving under the influence of marijuana from 2015-2018, and determined the impact of age and sex on engaging in driving under the influence of marijuana.

Methods: We analyzed cross-sectional population survey data using the Canadian Community Health Survey (2015, 2016, 2017 and 2018). Descriptive statistics and prevalence estimates were generated using proportions and bootstrapped confidence intervals. We used logistic regression to determine age and sex associations with driving under the influence of marijuana in the past year.

Results: Between 2015 and 2018, the highest rate of driving under the influence of marijuana occurred for males aged 15-24 years, and the lowest frequency was in women aged $25+$ years. These frequencies represent $2-3 \%$ of the total population in each year. Males were more likely to drive under the influence of marijuana in the past year compared with females in Alberta in 2015 (odds ratio [OR] 2.13, 95\% confidence interval [Cl] 1.124.06) and in Ontario in 2017 (OR 2.53, 95\% Cl 1.61-4.00). In Ontario, individuals aged 15-24 years were more likely to drive under the influence of marijuana than individuals aged 25 years and older when adjusted for sex in 2017 (OR 1.64, 95\% Cl 1.00-2.68) and 2018 (OR 1.91, 95\% Cl 1.16-3.15).

Conclusion: This characterization of trends for driving under the influence of marijuana at the population level should be considered by decision makers involved in the creation of healthy public policy.
WHAT WORKS? FOR WHOM? AND UNDER

WHAT CIRCUMSTANCE? A REALIST REVIEW OF INTERPROFESSIONAL EDUCATION INTERVENTIONS IN OBSTETRICS AND GYNECOLOGY

Nicole Delaloye ${ }^{1,2}$, Claire Lothian ${ }^{2}$

${ }^{1}$ Leaders in Medicine, ${ }^{2}$ Undergraduate Medical Education, Cumming School of Medicine, University of Calgary, Calgary, AB

Introduction: Obstetrics and gynecology requires healthcare professionals to collaborate in a variety of varying contexts. However, little guidance exists on how best to achieve this through interprofessional education (IPE) interventions. The aim of this study is to synthesize existing evidence examining the effectiveness of IPE interventions, within the context of obstetrics and gynecology.

Methods: MEDLINE, Embase, CINHAL, and ERIC will be systematically searched to identify primary research focusing on the evaluation of IPE interventions within the context of obstetrics and gynecology. Non-English studies will be excluded from a formal review. Abstracts and full text articles will be reviewed in duplicate. Only those studies that evaluate the effectiveness and implementation of IPE interventions will be included for the final analysis. A realist synthesis of the evidence based on Pawson's principles will then be undertaken.

Conclusion: Through a realist examination of the current evidence surrounding IPE in obstetrics and gynecology, we hope to identify the mechanisms that contribute to the success (or failure) of IPE within obstetrics and gynecology. This could potentially guide future educational practices, with the fundamental goal of cultivating collaborative healthcare professionals.

\section{EVALUATING AND ENHANCING THE PREPARATION OF FAMILIES BEFORE PEDIATRIC SURGERY}

Christopher Newell ${ }^{1 *}$, Heather Leduc-Pessah ${ }^{1 *}$, Lisa Bell-Graham², Nivez Rasic ${ }^{3,4}$, Kerryn Carter ${ }^{4}$

${ }^{1}$ Cumming School of Medicine, University of Calgary, ${ }^{2}$ Alberta Children's Hospital, ${ }^{3} \mathrm{ACHRI},{ }^{4}$ Section of Pediatric Anesthesiology, Department of Pediatrics, Calgary, AB ${ }^{*}$ co-first authors

Introduction: Surgery can be a difficult and unfamiliar experience for both children and their families. Existing information to prepare families for surgery at the Alberta Children's Hospital ( $\mathrm{ACH}$ ) includes various online resources and the Surgery 101 program; an in-person session to orient families to the hospital and experience. We sought to examine the effectiveness of the Surgery 101 program and evaluate the best way to enhance its content and accessibility. 
Methods: We developed an online survey for families who have had surgery at $\mathrm{ACH}$. Participants were recruited through pre-existing patient networks and from the ACH day surgery unit between Feb and Oct 2019. The survey asks participants to evaluate the information available to prepare them for surgery, including the Surgery 101 program, as well as requesting suggestions for improvement.

Results: Our survey results show that those who completed Surgery 101 felt significantly more prepared for surgery. Of those who did not attend Surgery 101, 50\% would have been interested in participating but were unaware that the program existed, and $18 \%$ planned to attend but were unable due to work or travel distance conflicts. Most participants felt that additional resources via online content or paper handouts would increase catchment of the Surgery 101 program.

Conclusion: We confirmed the efficacy of the Surgery 101 to prepare families for pediatric surgery and identified mechanisms to enhance the impact of the program. Our next steps include preparation of an online accessible version of Surgery 101 program for those who are unable to attend in person.

\section{INVESTIGATING THE IMPACT OF CO-DEBRIEFING ON TEAM PERFORMANCE OUTCOMES AMONG PRE-LICENSURE HEALTHCARE STUDENTS}

Gemma Percival', Amy Poelzer ${ }^{1}$, Irina Charania², Ian Wishart $^{1}$

${ }^{1}$ Undergraduate Medical Education, ${ }^{2}$ Advanced Technical Skills Simulation Lab, Cumming School of Medicine, Calgary, $A B$

Introduction: Research demonstrates that debriefing is a key aspect of simulation-based learning. To date the impact of interprofessional (IP) co-debriefing on student learning has not been investigated. Therefore, we explored the effect of IP co-debriefing on TEAM questionnaire scores.

Methods: Pre-licensure healthcare students were randomly assigned to IP groups. Students managed standardized patients portraying trauma victims. Teams completed their first simulation scenario and were subsequently debriefed by one or two facilitators. Students then participated in a second scenario with their same group. In total, 369 students (i.e., 152 medical, 157 nursing, 44 respiratory therapy and 16 paramedicine students) participated. Debrief facilitators included faculty and clinicians from medicine, nursing, and other allied health professions. To evaluate student teamwork performance, the Team Emergency Assessment Measure (TEAM), a previously validated assessment measure of teamwork during medical emergencies, was completed by facilitators and students.

Results: Facilitator ratings of student team performance in the two scenarios improved significantly for those assigned to single facilitator debriefing (39.21 to 51.74, $p<0.001)$. Facilitator ratings of team performance did not differ for those assigned to co-debriefing (45.05 and $47.54, p=n s)$. Student ratings indicated significant improvements in team performance in both single and co-debriefing conditions, 46.63 to 54.89, $\mathrm{p}<0.001$; and 50.91 to $54.02, p<0.001$, respectively.

Conclusion: Student ratings indicated an improvement of team performance for both debriefing conditions, while facilitator ratings indicated an improvement for only a single facilitator debriefing. Our results do not support the use of co-debriefing for achieving day-of performance improvement using the TEAM questionnaire.

\section{PERFUSION QUANTIFICATION DERIVED FROM CT} ANGIOGRAPHY TO PREDICT FINAL INFARCT VOLUME OBVIATES THE NEED FOR CINE CT PERFUSION ACQUISITION IN ACUTE ISCHEMIC STROKE-THE SIMPLE PERFUSION RECONSTRUCTION ALGORITHM (SPIRAL)

Leona L. Chan ${ }^{1,2}$, Connor C. McDougall ${ }^{1-6}$, Surbhi Sachan', Jen Guo', Rani G. Sah1,2,4, Bijoy Menon ${ }^{1-5}$, Andrew M.

Demchuk $^{1-4}$, Michael D. Hill'-4, Mayank Goyal ${ }^{2,4,5}$, Nils D. Forkert ${ }^{1,3,5}$, Christopher D. d'Esterre ${ }^{1-5}$, Philip A. Barber ${ }^{1-5}$

${ }^{1}$ Department of Clinical Neurosciences, University of Calgary, ${ }^{2}$ Seaman Family MR Research Centre, Foothills Medical Centre, ${ }^{3}$ Hotchkiss Brain Institute, University of Calgary, ${ }^{4}$ Calgary Stroke Program, University of Calgary, ${ }^{5}$ Department of Radiology, University of Calgary, ${ }^{6}$ Department of Mechanical Engineering, University of Calgary, Calgary, $A B$

Introduction: Infarct core volumetrics using CT perfusion (CTP) at patient admission is a mainstay paradigm for stroke treatment decision. Yet, there are several downfalls with cine CTP technology that can be overcome by adopting the Simple Perfusion Reconstruction Algorithm (SPIRAL). We compare SPIRAL, a perfusion map derived from a helical CT angiography, to GE-CT perfusion Tmax and CBF to predict final infarction at 24 hours.

Methods: 72 patients had admission NCCT, multi-phase CTA and CTP imaging. All patients underwent EVT and had successful and quality reperfusion Thrombolysis in Cerebral Ischemia 2b or 3. Twenty-four hour MRI was performed to delineate the final infarct volume. Patient-level and Cohort-level Receiver Operator Characteristic curves were generated to determine accuracy for final infarct volume. A 10-fold cross validation was also performed on the cohort level data. We also compared the accuracy of SPIRAL and GE-CTP maps for the detection of the 24-hour MRI volume. 
Results: In the patient-level ROC analysis, the SPIRAL map had slightly higher, though non-significant $(p<0.05)$ ROC-AUC than both CTP-Tmax and CTP-CBF functional maps. The same relationship was observed at the cohort level. The cross-validation ROC-AUC was highest with CTP-Tmax functional maps (AUC 0.87), but was not significantly different (AUC 0.83). SPIRAL was significantly less sensitive to smaller lesions (1-10 cc, $70-75 \%)$, while equally as accurate to larger lesions (>100 cc, 85-87\%) compared with GE-CTP.

Conclusion: Perfusion functional maps can be successfully generated from a temporally-sampled helical CTA, obviating the need for an additional cine CTP scan.

\section{TRACKING WHITE MATTER NEUROPLASTICITY USING BOLD FMRI}

Lukas A. Grajauskas $^{1-3}$, Tony Frizzell ${ }^{3,4}$, Sujoy Hajra ${ }^{3,4}$, Caressa Liu $^{3,4}$, Xiaowei Song ${ }^{2,3}$, Ryan CN D'Arcy ${ }^{2-5}$

${ }^{1}$ Cumming School of Medicine, University of Calgary, Calgary, AB, ${ }^{2}$ Department of Biomedical Physiology and Kinesiology, Simon Fraser University, Burnaby, BC, ${ }^{3}$ ImageTech Lab, Surrey Memorial Hospital, Fraser Health, Surrey, BC, ${ }^{4}$ Faculty of Applied Sciences, Simon Fraser University, Burnaby, BC, ${ }^{5}$ Djavad Mowafaghian Centre for Brain Health, University of British Columbia, Vancouver, $\mathrm{BC}$

Introduction: Modulation of white matter within the brain is understood to be a vital part of motor learning; however, because of limited methods available to track functional changes in white matter in vivo, investigations of grey matter changes have dominated research surrounding neuroplasticity. The application of BOLD fMRI to white matter is becoming more accepted, although there is no work to date specifically looking at neuroplasticity.

Results: Here, 12 healthy right-handed participants received a baseline fMRI scan, in which they completed a fine motor and a gross motor task with both their left and right hands using an MRI compatible computer mouse. The motor tasks were designed to be difficult for only the left-hand fine motor task, selectively driving motor training in only that condition. Participants then practiced the two tasks using their left and right hands on their personal computer over the course a two-week training interval, and received a follow-up fMRI scan. A statistically significant improvement in the motor task score was noted only for the left hand fine motor condition ( $p<0.01)$, allowing for a comparison between tasks and lateralized motor control regions in each hemisphere.

Conclusion: We saw a corresponding change in the temporal characteristics of the hemodynamic response within the left corticospinal tract but not the right, with a more dispersed hemodynamic response occurring after the two-week training period. This suggests that modification of the temporal dynamics, rather than the extent of activation, may underly the functional changes seen white matter neuroplasticity.

\section{COMPARING THE PROGRESSION OF UPPER MOTOR NEURON DEGENERATION BETWEEN AMYOTROPHIC LATERAL SCLEROSIS PATIENTS WITH AND WITHOUT EXECUTIVE DYSFUNCTION}

Emily Mostofi', Abdullah Ishaque ${ }^{1,2}$, Angela Genge ${ }^{3}$, Lorne Zinman ${ }^{4}$, Christian Beaulieu ${ }^{5}$, Simon J. Graham ${ }^{4}$, Pascal Tetreault ${ }^{5}$, Sanjay Kalra ${ }^{1,6}$ for the Canadian ALS Neuroimaging Consortium

${ }^{1}$ Neuroscience and Mental Health Institute, University of Alberta, Edmonton, AB, ${ }^{2}$ Faculty of Medicine and Dentistry, University of Alberta, Edmonton, $A B,{ }^{3}$ Montreal Neurological Institute and Hospital, McGill University, Montreal, QC, "S Sunnybrook Hospital, University of Toronto, Toronto, ON, ${ }^{5}$ Department of Biomedical Engineering, University of Alberta, Edmonton, AB, ${ }^{6}$ Division of Neurology, Department of Medicine, University of Alberta, Edmonton, $A B$

Introduction: Amyotrophic lateral sclerosis (ALS) is a rapidly progressive motor neuron disease characterized by both upper (UMN) and lower motor neuron (LMN) degeneration. In addition to motor impairments, approximately $30-50 \%$ of ALS patients also experience variable degrees of cognitive and behaviour impairment. Such impairment, particularly in the domain of executive dysfunction, has been linked to a faster motor functional decline and reduced survival in ALS patients. These findings may be associated with biological mechanisms that augment UMN degeneration in patients with cognitive impairment. In this study we aimed to evaluate whether ALS patients with executive dysfunction experience more UMN degeneration over time.

Methods: Diffusion tensor imaging and tract-based spatial statistics analyses were used to measure and compare UMN degeneration between ALS patients with and without executive dysfunction both at baseline and over time.

Results: Baseline analysis showed that our cohort of ALS patients with executive dysfunction had a greater spatial extent of degeneration in the corticospinal tract (CST), corpus callosum (CC) and precentral gyrus compared with patients without dysfunction. Longitudinal analysis showed that in patients with executive dysfunction, progressive degeneration was widespread in the CST, CC, brainstem, thalamus, temporal and frontal lobes, while ALS patients without executive dysfunction showed 
progressive degeneration only in the CC.

Conclusion: This study supports the theory that ALS patients with executive dysfunction experience more UMN degeneration over time compared with patients without dysfunction, while also experiencing more degeneration in other motor and extra-motor areas of the brain.

\section{A SURPRISING NEUROPROTECTIVE ROLE FOR AMYLOID BETA DURING ISCHEMIC STROKE}

Laura A. Palmer ${ }^{1,2}$, Andrew K.J. Boyce ${ }^{1,2}$, Tal Tanne ${ }^{1,2}$, Alexander W. Lohman ${ }^{1,2}$, S.R. Wayne Chen ${ }^{1,3,4}$, Roger J Thompson ${ }^{1,2}$

${ }^{1}$ Hotchkiss Brain Institute, Cumming School of Medicine, ${ }^{2}$ Department of Cell Biology \& Anatomy, Cumming School of Medicine, ${ }^{3}$ Department of Physiology \& Pharmacology, Cumming School of Medicine, ${ }^{4}$ Department of Biochemistry and Molecular Biology, Cumming School of Medicine, University of Calgary, Calgary, AB

Introduction: Ischemic stroke is an important risk factor for developing Alzheimer disease (AD), and upregulates the $A D$-associated protein, $A \beta$. Due to the toxic role $A \beta$ plays in $A D$, we hypothesized that $A \beta$ enhances excitotoxicity during ischemia. Anoxic depolarization (aDP) is an excitotoxic event that occurs in response to ischemic glutamate release, activating NMDA receptors (NMDARs). Previously, we demonstrated activation of pannexin-1 (Panx1) channels downstream of NMDARs to contribute to excitotoxicity during the aDP. Metabotropic glutamate receptors (mGluRs) enhance NMDAR activation during excitotoxicity, suggesting a potentially convergent signalling pathway to open Panx1. Since NMDARs/mGluRs are known targets of $A \beta$, we hypothesized that $A \beta$ could modify Panx1 opening.

Methods: Using whole-cell patch clamp electrophysiology and 2-photon microscopy in rodent hippocampal slices, excitotoxicity was assayed under low oxygen. We are developing a novel in vivo mouse model to image $\mathrm{Ca} 2+$ dysregulation during ischemia.

Results: Surprisingly, we found $A \beta$ to be protective and to reduce Panx1 opening during the aDP. An AD mouse model had reduced aDPs and ischemic Ca2+ dysregulation dependent on $A \beta$ load. Low concentrations ( $p M$ to $n M$ ) of synthetic $A \beta$ attenuated the aDP and blocked Panx1 opening in response to NMDA overstimulation. The protective effect by $A \beta$ required binding to mGluR1 to reduce opening of Panx1 in a Src kinase-dependent manner.

Conclusion: These data reveal a novel modulation of Panx1 opening by mGluR1, which is regulated by $A \beta$.
$A \beta$ production could be increased during ischemia to reduce activation of Panx1, thereby attenuating excitotoxicity and downstream cell death pathways.

THE LINEAR OBLIQUE CRANIECTOMY FOR SUBDURAL GRID INSERTION

Calvin W. Howard', Nader Aboelnazaar², Noor Salem³, Naweed Syed ${ }^{2,3}$, Lian Willets ${ }^{2}$

${ }^{1}$ Cumming School of Medicine, University of Calgary, ${ }^{2}$ Department of Cell Biology \& Anatomy, University of Calgary, ${ }^{3}$ Alberta Children's Hospital Research Institute, Calgary, $A B$

Introduction: Many countries rely upon subdural grid electroencephalography in the pre-operative planning of epilepsy surgeries. However, craniectomy for subdural grid implantation is known to result in a variety of complications and requires diligence from the surgical team. Here, we describe a minimally invasive method of subdural grid insertion, termed the linear oblique craniectomy, designed to mitigate these complications and increase ease of subdural grid insertion.

Methods: Three fresh frozen and embalmed human cadavers underwent extensive surface anatomical landmarking of craniectomy locations to introduce a $4 \mathrm{~cm} \mathrm{x}$ $5 \mathrm{~cm}$ subdural grid over the Sylvian Fissure. An incision was made in the soft tissue $8 \mathrm{~cm}$ posterior to the supraorbital ridge and $2 \mathrm{~cm}$ medial to the superior temporal line. A $5 \mathrm{~cm} \times 1 \mathrm{~cm}$ at maximal width lens-shaped craniectomy was created anteroposteriorly. The subdural grid was inserted and imaged with X-ray, CT and MRI to verify location over the Sylvian Fissure.

Results: The total area of the linear oblique craniectomy consists of only $10 \%$ of the total area removed by the traditional approach to access the Sylvian Fissure for mesial-temporal epilepsy monitoring/pre-operative planning. Damages to the middle meningeal arteries were avoided successfully in all trials. The grids were accurately placed over the Sylvian Fissure in all trials.

Conclusion: The linear oblique craniectomy procedure provides an alternative approach to subdural grid implantation with significantly decreased invasiveness. This surgical approach has the potential of reducing complication rates of subdural grid insertion in diagnostics, pre-operative planning, and brain-machine interfacing. 


\section{ABBREVIATED POSTER ABSTRACTS}

The following are titles and authors of abstracts presented in poster format.

Name underlined indicates the poster presenter.

REANALYSIS OF WHOLE EXOME SEQUENCING DATA

IN A COHORT OF UNDIAGNOSED INDIVIDUALS WITH NEURODEVELOPMENTAL DISORDERS

Danielle C. Lynch', Melanie Keller², A. Micheil Innes ${ }^{2,3}$

${ }^{1}$ Cumming School of Medicine, University of Calgary, ${ }^{2}$ Cumming School of Medicine, University of Calgary, ${ }^{3} \mathrm{Al}-$ berta Children's Hospital Research Institute, Calgary, AB

PREVENTING THE EMERGENCE OF TEMOZOLOMIDE RESISTANCE IN GLIOBLASTOMA BY PARP-1 INHIBITION

Alice L. Yuan ${ }^{1,2}$, Elizabeth A Bering ${ }^{1,2}$, Jacob Willms ${ }^{1,2}$, Melanie Tan ${ }^{1,2}$, Michael D. Blough ${ }^{1-3}$, J. Gregory Cairncross ${ }^{1-5}$

${ }^{1}$ Clark H. Smith Brain Tumor Centre, ${ }^{2}$ Arnie Charbonneau Cancer Institute, ${ }^{3}$ Department of Clinical Neurosciences, ${ }^{4}$ Department of Oncology, ${ }^{5}$ Hotchkiss Brain Institute, University of Calgary, Calgary, $A B$

INDUCED EXTRACELLULAR MATRIX DEGENERATION IN HUMAN AORTIC MYOFIBROBLASTS: A MECHANISM OF FLUOROQUINOLONE-ASSOCIATED AORTOPATHY

David G. Guzzardi, Guoqi Teng, Sean Kang, Patrick J. Geeraert, Simranjit S. Pattar, Daniyil A. Svystonyuk, Darrell D. Belke, Paul W. M. Fedak

Section of Cardiac Surgery, Department of Cardiac Science, Libin Cardiovascular Institute of Alberta, Cumming School of Medicine, University of Calgary, Calgary, AB

DEPRESSION, ANXIETY, AND POSTTRAUMATIC STRESS SYMPTOMS IN MOTHERS WITH PREECLAMPSIA AND THEIR PARTNER

Courtney Schubert', Andrea Nelson ${ }^{2}$, Kamran Yusuf ${ }^{3}$ 'Undergraduate Medical Education, University of Calgary, ${ }^{2}$ Alberta Health Services, ${ }^{3}$ Department of Pediatrics, University of Calgary, Calgary, $A B$

\section{A ROLE FOR THE LYSOSOMAL THIOL REDUCTASE GILT IN} OSTEOCLASTIC BONE RESORPTION.

Benjamin W. Ewanchuk ${ }^{1,2}$, Corey R. Arnold ${ }^{1,2}$, Dale R. Balce ${ }^{1,3}$, Priyatha Premnath ${ }^{4}$, Roman J. Krawetz ${ }^{4}$, and Robin M. Yates ${ }^{1,2,3}$

'The Calvin, Phoebe and Joan Snyder Institute for Chronic Diseases, ${ }^{2}$ Department of Biochemistry \& Molecular Biology, ${ }^{3}$ Department of Comparative Biology \& Experimental Medicine, ${ }^{4}$ Department of Cell Biology \& Anatomy, University of Calgary, Calgary, $A B$
WHITE MATTER TRACT DEVELOPMENTAL TRAJECTORIES OF AXONAL DENSITY IN EARLY CHILDHOOD

Dennis Dimond', Stella Heo', Amanda Ip', Christiane S. Rohr', Thijs Dhollander ${ }^{2}$, Robert E. Smith ${ }^{2}$, Ivy $\mathrm{Cho}^{3}$, Catherine Lebel', Deborah Dewey', Alan Connelly², Signe Bray'

'University of Calgary, Calgary, AB, ${ }^{2}$ The Florey Institute of Neuroscience and Mental Health, Melbourne, VIC, Australia, ${ }^{3}$ The University of Toronto, Toronto, ON

REDUCED CEREBRAL BLOOD FLOW MEASURED IN THE EAE MOUSE MODEL OF MULTIPLE SCLEROSIS USING PERFUSION MRI

Max A. Hamilton ${ }^{1,2,3,4}$, Tom Johnson ${ }^{1,2,3,4}$, Taelor Evans ${ }^{1,2,3,4}$, Erin Stephenson ${ }^{2,3}$, Wee V. Yong ${ }^{2,3}$, Jeff F. Dunn $n^{1,2,3,4}$

'Department of Radiology, ${ }^{2}$ Department of Clinical Neuroscience, ${ }^{3}$ Hotchkiss Brain Institute, ${ }^{4}$ Experimental Imaging Centre, Cumming School of Medicine, University of Calgary, Calgary, AB

REPETITIVE TRANSCRANIAL MAGNETIC STIMULATION AS A TREATMENT FOR TOURETTE'S SYNDROME IN CHILDREN: A PILOT STUDY

Cynthia K. Kahl', Adam Kirton ${ }^{2,3}$, Tamara Pringsheim²,3,4, Paul Croarkin ${ }^{5}$, Ephrem Zewdie ${ }^{2}$, Rose Swansburg ${ }^{2,4}$, Frank P. MacMaster ${ }^{2,4}$

'Department of Neuroscience, University of Calgary, Calgary $A B,{ }^{2}$ Department of Pediatrics, University of Calgary, Calgary $A B$, ${ }^{3}$ Department of Clinical Neurosciences, University of Calgary, Calgary $A B,{ }^{4}$ Department of Psychiatry, University of Calgary, Calgary AB, ${ }^{5}$ Departments of Psychiatry and Psychology, Mayo Clinic, Rochester MN, USA

\section{QUANTIFYING SPECIES SELECTION}

Brian D. Rankin1, Jeremy W Fox², Christina R. Barrón-Ortiz ${ }^{3}$, Amy E. Chew ${ }^{4}$, Patricia A. Holroyd ${ }^{5}$, Joshua A. Ludtke ${ }^{2}$, Xingkai Yang'2 Jessica M. Theodor ${ }^{2}$

'Cumming School of Medicine, University of Calgary, Calgary, $A B,{ }^{2}$ Department of Biological Sciences, University of Calgary, Calgary, AB, ${ }^{3}$ Royal Alberta Museum, Edmonton, $A B,{ }^{4}$ Department of Anatomy, Brown University, Providence, RI, USA, ${ }^{5}$ Museum of Paleontology, University of California, Berkeley, CA, USA

PRIMARY CUTANEOUS CD4+ SMALL/MEDIUM-SIZED PLEOMORPHIC T-CELL LYMPHOPROLIFERATIVE DISORDER: THE ALBERTA PERSPECTIVE AND REVIEW OF THE LITERATURE

Sean Doherty', Philip Surmanowicz', Amy Du³, Jori Har$\operatorname{din}^{1,2}$, Robert Gniadecki, ${ }^{3,4}$

'Division of Dermatology, University of Calgary, Calgary 
$A B$, 2Department of Medicine, University of Calgary, Calgary $A B,{ }^{3}$ Division of Dermatology, University of Alberta, Edmonton $A B,{ }^{4}$ Department of Medicine, University of Alberta, Edmonton $A B$

\section{A REVIEW OF FIFTEEN YEARS OF PEDIATRIC INFECTIOUS DISEASE ADMISSIONS TO TWO REFERRAL HOSPITALS FROM RURAL COMMUNITIES OF NORTHERN BRITISH COLUMBIA AND THE YUKON}

Celia Walker', Niranjan Kissoon², Matthew Wiens ${ }^{3}$, Jennifer Smitten ${ }^{2}$, Theresa McElroy ${ }^{4}$, Tahir Chaudhry ${ }^{5}$, Jeffrey Bone $^{6}$, Manish Sadarangani ${ }^{2}$, David M. Goldfarb ${ }^{1,2}$

'Department of Pathology \& Laboratory Medicine, BC Children's Hospital, Vancouver, BC, ${ }^{2}$ Department of Pediatrics, BC Children's Hospital, Vancouver, BC, ${ }^{3}$ University of British Columbia, Faculty of Medicine, Vancouver, BC, ${ }^{4} U$ niversity of British Columbia, Department of Occupational Science and Occupational Therapy, Vancouver, BC, ${ }^{5}$ University Hospital of Northern British Columbia, Department of Pediatrics, Prince George, BC, ${ }^{6}$ University of British Columbia, Department of Obstetrics and Gynecology, Vancouver, BC

\section{STING ACTIVATION AS AN IMMUNOTHERAPEUTIC STRATEGY FOR SOFT TISSUE SARCOMA}

Kayla Marritt ${ }^{1-3}$, Arvind Singla ${ }^{1-3}$, Asmaa Affan ${ }^{1-3}$, Karys Hildebrand ${ }^{1-3}$, Kurt Hildebrand ${ }^{1-3}$, Frank Jirik ${ }^{3,4}$, Michael Monument ${ }^{1-3}$

${ }^{1}$ Department of Surgery, ${ }^{2}$ Arnie Charbonneau Cancer Institute, ${ }^{3} \mathrm{McC}$ aig Institute for Bone and Joint Health, 4Department of Biochemistry \& Molecular Biology, Cumming School of Medicine, University of Calgary, Calgary, AB

\section{INVESTIGATING INFECTION OF THE TUMOUR} MICROENVIRONMENT FOLLOWING INTRAVENOUS TREATMENT WITH ONCOLYTIC VESICULAR STOMATITIS VIRUS

Madison Turk ${ }^{1,2,3}$, Victor Naumenko ${ }^{6}$, Jahanara Rajwani ${ }^{2,3,4}$, Kyle Potts ${ }^{1,2,3}$, Franz Zemp ${ }^{1,2,3}$, Agostina Carestia ${ }^{1,5}$, Doug Mahoney ${ }^{1,2,3,4}$, Craig Jenne1, ${ }^{1,5}$

'Department of Microbiology, Immunology and Infectious Disease, University of Calgary AB, ${ }^{2}$ Alberta Children's Hospital Research Institute, Calgary, $A B,{ }^{3}$ Arnie Charbonneau Cancer Institute, Calgary, AB, ${ }^{4}$ Department of Biochemistry and Molecular Biology, Faculty of Medicine, University of Calgary, Calgary, AB, ${ }^{5}$ Department of Critical Care Medicine, Faculty of Medicine, University of Calgary, Calgary, AB, ${ }^{6}$ National University of Science and Technology "MISIS", Leninskiy prospect, Moscow, Russia
A REVIEW OF GENE EXPRESSION PROFILING IN EARLYSTAGE ER+/HER2- BREAST CANCER WITH A FOCUS ON THE PAM50 RISK OF RECURRENCE ASSAY

Malek B. Hannouf ${ }^{1}$, Christine Brezden-Masley ${ }^{2,3}$, Jacques Raphael', Muriel Brackstone $^{1}$

${ }^{1}$ Department of Oncology, Schulich School of Medicine and Dentistry, Western University, London Regional Cancer Program, London, ON, ${ }^{2}$ Faculty of Medicine, University of Toronto, Toronto, ON, ${ }^{3}$ Division of Hematology and Oncology, St. Michael's Hospital, Toronto, ON

THE COMBINATION OF THE PARP INHIBITOR OLAPARIB AND THE ATR INHIBITOR VE-821 SELECTIVELY TARGETS ATM-DEFICIENT LUNG CANCER CELLS

Nicholas Jette', S. Radhamani', G. Arthur1, R. Ye', S. Goutam¹, A. Boylos', L. Peterson², P. Bose',2, G. Bebb², S. Lees-Miller ${ }^{1,2}$

'Departments of Biochemistry and Molecular Biology, Robson DNA Science Centre and Charbonneau Cancer Institute, Cumming School of Medicine, University of Calgary, ${ }^{2}$ Department Oncology, Robson DNA Science Centre and Charbonneau Cancer Institute, Cumming School of Medicine, Calgary, AB

PROTEINASE ACTIVATED RECEPTOR (PAR) 1 IS SELFACTIVATED BY HIGH GRADE UROTHELIAL CARCIONMA CELLS TO DRIVE MIGRATION

Stacy de Lima ${ }^{1,2}$, Mihara Koichiro ${ }^{1,2}$, Eric Hyndman ${ }^{3}$, and Morley Hollenberg ${ }^{1,2}$

IInflammation Research Network-Snyder Institute for Chronic Diseases, University of Calgary Cumming School of Medicine, ${ }^{2}$ Department of Physiology and Pharmacology \& Department of Medicine, University of Calgary, ${ }^{3}$ Southern Alberta Institute of Urology, Calgary, AB

\section{MITIGATING POST-CARDIAC SURGICAL ADHESION FORMATION}

Ali Fatehi Hassanabad', Jeannine Turnbull', Simranjit S. Pattar', Darrell Belke', Guoqi Teng', Sean Kang', Justin Deniset $^{2}$, Rachel Kratofil², Suresh Regmi³ ${ }^{3}$ Daniyil A. Svystonyuk', Jameson Dundas' ${ }^{1}$ Dan S.J. Park ${ }^{4}$, Tannin Schmidt ${ }^{5}$, Paul W.M. Fedak ${ }^{1}$

'Section of Cardiac Surgery, Department of Cardiac Sciences, University of Calgary, Calgary, AB, ${ }^{2}$ Department of Immunology, Snyder Institute for Chronic Diseases, University of Calgary, Calgary, AB, ${ }^{3}$ Department of Kinesiology, University of Calgary, Calgary, $A B,{ }^{4}$ Faculty of Medicine, University of Toronto, Toronto, ON, ${ }^{5} \mathrm{Biomedi}-$ cal Engineering Department, University of Connecticut, Farmington, CT, USA 
THE ROLE OF PHOSPHORYLATION IN THE REGULATION OF YEAST GLYCEROPHOSPHATE ACYLTRANSFERASE GPT2

Anabel Cardenas Rivas ${ }^{1}$, Vanina Zaremberg ${ }^{1}$, Marjan Tavasssoli ${ }^{1}$

${ }^{1}$ Department of Biological Sciences, University of Calgary, Calgary, $A B$

CHARACTERIZATION OF DIHYDROXYACETONE PHOSPHATE ACYLTRANSFERASE (DHAPAT)

Łingjie Duanmu ${ }^{1}$, Maxwell Chilije', Vanina Zaremberg ${ }^{1}$

'Department of Biological Sciences, University of Calgary, Calgary, AB

RETINAL PIGMENT EPITHELIUM MICROTISSUES EXHIBIT INCREASED RELEASE OF PEDF AND ENHANCE PHOTORECPETOR SURVIVAL

Abdullah Al-Ani ${ }^{1,2,3,4}$, Derek Toms ${ }^{3,5}$, Kayla Giles ${ }^{5}$, Yacine Touahrii, ${ }^{3,6,7}$, Saud Sunba ${ }^{5}$, Carol Schuurmans ${ }^{3,6,7}$, Mark Ungrin $^{2,3,5}$

'Biomedical Engineering Graduate Program, University of Calgary, Calgary, AB, ${ }^{2}$ Alberta Diabetes Institute, University of Alberta, Edmonton, $A B,{ }^{3}$ Alberta Children's Hospital Research Institute, University of Calgary, Calgary, $A B$, ${ }^{4}$ Leaders in Medicine Program, Cumming School of Medicine, University of Calgary, Calgary, AB, ${ }^{5}$ Department of Comparative Biology and Experimental Medicine, Faculty of Veterinary Medicine, University of Calgary, Calgary, $A B,{ }^{6}$ Biological Sciences Platform, Sunnybrook Research Institute, Toronto, ON, ${ }^{7}$ Department of Biochemistry and Molecular Biology, Cumming School of Medicine, University of Calgary, Calgary, AB

\section{SENESCENCE OF MESENCHYMAL PROGENITORS DRIVES AGE-ASSOCIATED HAIR FOLLICLE DEGENERATION}

Wisoo Shin ${ }^{1}$, Nicole L. Rosin ${ }^{1,5}$, Holly Sparks ${ }^{1,5}$, Sarthak Sinha', Waleed Rahmani', Nilesh Sharma', Matt Workentine', Sepideh Abbasi', Jo A. Stratton ${ }^{1,2}$, Jeff Biernaskie ${ }^{1,2,3,4,6}$

${ }^{1}$ Department of Comparative Biology and Experimental Medicine, Faculty of Veterinary Medicine, ${ }^{2}$ Hotchkiss Brain Institute, Cumming School of Medicine, ${ }^{3}$ Department of Surgery, Cumming School of Medicine, ${ }^{4}$ Alberta Children's Hospital Research Institute, University of Calgary, Calgary, AB

\section{A STUDY OF THE FACILITATING AND HINDERING FACTORS IN THE COMPREHENSION AND USE OF INFORMATION ABOUT CHILDREN AND TODDLERS' ORAL HEALTH BY PARENTS AND CAREGIVERS}

Margareth Zanchetta', Wilson G. Garcia², Annita V. Morei$\underline{\mathrm{ra}}^{3}$
'Daphne Cockwell School of Nursing, Ryerson University, Toronto, ON, ${ }^{2}$ Department of Dentistry, São Paulo State University (UNESP), Araçatuba, Sao Paulo, Brazil, 3'Daphne Cockwell School of Nursing, Ryerson University, Toronto, ON

\section{EVALUATION OF A HEALTH PROMOTION WORKSHOP INTERVENTION FOR SOCIALLY VULNERABLE ADULTS IN CALGARY}

Helen Cai ${ }^{1}$, Laura Rivera', Erin Kelly', Andrew Wong², Chris Sciberras $\mathrm{MC}^{3}$

${ }^{1}$ Cumming School of Medicine Student Run Clinic, ${ }^{2} \mathrm{Cum}-$ ming School of Medicine Department of Family Medicine, ${ }^{3}$ Calgary Dream Center, Calgary $A B$

TAKING THE NEXT STEP: A CASE STUDY IN DECISIONMAKING, VALUE-SPACE, AND AUTONOMY OF ONE'S BODY

$\underline{\text { Ian MacNairn }}$

Department of Anthropology and Cumming School of Medicine, Leaders in Medicine Program; University of Calgary, Calgary, AB

\section{NEIGHBOURHOOD UPGRADING IN TUNISIA: CONNECTING INFORMAL HOUSING WITH BASIC SERVICES}

Wendy Yao ${ }^{1,2}$, Kirstyn Koswin², Cadhla Gray², Bruno Câmara Pinto ${ }^{2}$, Tina Vulevic' ${ }^{2}$, Joseph Wong²

${ }^{1}$ Cumming School of Medicine, University of Calgary, Calgary, AB, ${ }^{2}$ REACH Project, Munk School of Global Affairs, University of Toronto, Toronto, ON

\section{HYPERVIRULENT CRYPTOCOCCUS GATTII BLOCKS HUMAN DC COSTIMULATION VIA F-ACTIN CAGE MEDIATED PHAGOSOMAL ARREST}

Khusraw Jamil ${ }^{1,2}$, David D. Feehan ${ }^{1,2}$, Shushun Li ${ }^{1,2}$, Danuta Stack $^{1,2}$, Maria Polyak ${ }^{1,2}$, Anutosh Ganguly ${ }^{1,3}$, Christopher H. Mody $y^{1,2,4}$

${ }^{1} T$ he Calvin, Phoebe and Joan Snyder Institute for Chronic Diseases, University of Calgary, Calgary AB, ${ }^{2}$ Department of Microbiology, Immunology and Infectious Diseases, University of Calgary, Calgary $A B,{ }^{3}$ Department of Surgery, University of Michigan, Ann Arbor, MI, USA, ${ }^{4}$ Department of Medicine, University of Calgary, Calgary, AB

\section{THE FUNCTIONAL INTERPLAY BETWEEN THE INTESTINAL} MICROBIOTA, T CELLS, AND IMMUNOGLOBULINS

Mia Koegler ${ }^{1}$, Regula Burkhard ${ }^{1}$, Markus Geuking ${ }^{1}$

'Department of Microbiology, Immunology, and Infectious Diseases, Snyder Institute for Chronic Diseases, Cumming School of Medicine, University of Calgary, Calgary, $A B$ 
IS WORM THERAPY AN EFFECTIVE TREATMENT FOR CROHN'S DISEASE? A STUDY OF GUT PATHOLOGY AND EOSINOPHIL POPULATIONS

Namratha Badawadagi ${ }^{1,2}$, Camila Gaio ${ }^{1,2}$, Anupama Ariyaratne ${ }^{1,2}$, Bjorn Petri ${ }^{1,3}$, Kamala Patel ${ }^{3}$, Edina Szabo ${ }^{1,2}$, Constance Finney ${ }^{1,2}$

${ }^{1}$ Faculty of Science, ${ }^{2}$ Host Parasite Interactions, ${ }^{3}$ The Calvin, Phoebe and Joan Snyder Institute for Chronic Diseases, University of Calgary, Calgary, AB

THE CROHN'S DISEASE PATHOBIONT ADERENT-INVASIVE E. COLI INDUCES MITOCHONDRIAL FISSION LEADING TO LOSS OF BARRIER FUNCTION AND WOUND REPAIR CAPACITY OF THE EPITHELIUM

Nicole L. Mancini, Timothy S. Jayme, Arthur Wang, Jane Shearer, Derek M. McKay

Gastrointestinal Research Group, Department of Physiology \& Pharmacology, Snyder Institute for Chronic Disease, Cumming School of Medicine, University of Calgary, Calgary, $A B$

PLANKTONIC AND BIOFILM FORMING PSEUDOMONAS AERUGINOSA ELICITS DIFFERENTIAL AND SEX SPECIFIC NEUTROPHILIC RESPONSES DURING PULMONARY INFECTION

Elise Granton $^{1,2}$, Bryan G. Yipp ${ }^{1,2}$

${ }^{1}$ Calvin, Phoebe and Joan Snyder Institute for Chronic Diseases, ${ }^{2}$ Department of Critical Care Medicine, Cumming School of Medicine, University of Calgary, Calgary, $\mathrm{AB}$

PEAK SYSTOLIC LOAD PREDICTS OUTCOMES AND CORRELATES TO REGIONAL MRI STRAIN PATTERN IN HYPERTROPHIC CARDIOMYOPATHY

Payam Pournazari, Fadi Ibrahim, Andrew Grant Libin Cardiovascular Institute, Cumming School of Medicine, University of Calgary

NUTRITION, GUT HEALTH, AND INFLAMMATION IN ANOREXIA NERVOSA AND OBSESSIVE-COMPULSIVE DISORDER: A PROPOSED INVESTIGATION

Emily CM Macphail ${ }^{1,2,4}$, Raylene Reimer ${ }^{3,4,5}$, Paul Arnold ${ }^{1,2,4}$

${ }^{1} T$ The Mathison Centre for Mental Health Research and Education, University of Calgary, ${ }^{2}$ Hotchkiss Brain Institute, University of Calgary, ${ }^{3} \mathrm{Alberta}$ Children's Hospital Research Institute, ${ }^{4}$ Cumming School of Medicine, University of Calgary, ${ }^{5}$ Faculty of Kinesiology, University of Calgary, Calgary, AB
FEVER AND NECK MASS IN A RETURNING TRAVELLER DIAGNOSED AS SYSTEMIC LUPUS ERYTHEMATOSUS

Naman Siddique ${ }^{1}$, Stuart Wiber ${ }^{1,2,4}$, Michelle Grinman ${ }^{1,2,3}$, Dianne Mosher ${ }^{1,2,4}$

${ }^{1}$ Cumming School of Medicine, ${ }^{2}$ Department of Medicine, ${ }^{3}$ Division of General Internal Medicine, ${ }^{4}$ Division of Rheumatology, University of Calgary, Calgary, AB

\section{EFFECT OF VILANTEROL TRIFENATATE/FLUTICASONE} FUROATE ON PARASTERNAL INTERCOSTAL MUSCLE RAW EMG ACTIVITY IN SEVERE COPD: TURNS AND CENTROID FREQUENCY ANALYSIS

Michael Ji', Ron S. Platt', Jenny V. Suneby Jagers', Giovanni Tagliabue', Eric R. Wilde', Paul A. Easton ${ }^{1}$

${ }^{1}$ Lethbridge Regional Hospital, Department of Critical Care Medicine, Lethbridge, $A B$

\section{IS CAREGIVER-DETECTED DELIRIUM ASSOCIATED WITH} SYMPTOMS OF DEPRESSION AND ANXIETY IN CAREGIVERS OF THE CRITICALLY ILL?

Brianna K Rosgen ${ }^{1,2}$, Karla D Krewulak', Henry T Stelfox ${ }^{1,2,3}$, E Wesley Ely ${ }^{4}$, Judy E Davidson ${ }^{5}$, Kirsten M Fiest ${ }^{1,2,3,6}$

'Department of Critical Care Medicine, University of Calgary, Calgary, AB, ${ }^{2}$ Department of Community Health Sciences, University of Calgary, Calgary, $A B,{ }^{3} A$ lberta Health Services, "Tennessee Valley Veteran's Affairs Geriatric Research Education Clinical Center (VA GRECC), Department of Medicine, Center for Health Services Research and Division of Pulmonary and Critical Care Medicine, ${ }^{5}$ University of California San Diego, CA, USA, ${ }^{6}$ Department of Psychiatry, University of Calgary, Calgary, $A B$

\section{ADDRESSING PROCESS IMPROVEMENT IN ADVANCE CARE} PLANNING: A PRE-POST INTERVENTION STUDY IN THE CARDIAC SETTING

Marta Shaw, Jayna Holroyd-Leduc, Jessica Simon

Community Health Sciences, University of Calgary, Calgary, $A B$

DEVELOPMENT, IMPLEMENTATION, AND INTERIM EVALUATION OF A PHYSICIAN AUDIT AND FEEDBACK REPORT TO REDUCE INJURY TO THE KIDNEYS DURING CARDIAC CATHETERIZATION

Bryan Ma1, Michelle M. Graham ${ }^{2,3}$, Bryan J. Har ${ }^{4,5}$, Benjamin D. Tyrrell ${ }^{2,6}$, Peter Faris ${ }^{7,8}$, Stephen B. Wilton ${ }^{4,5,7,9}$, Merril L. Knudtson ${ }^{1,4}$, Neesh Pannu², Tolulope T. Sajobi ${ }^{5,7,9}$, John A. Spertus $^{10}$, Matthew T. James ${ }^{1,5,7,9}$

${ }^{1}$ Department of Medicine, Cumming School of Medicine, University of Calgary, Calgary, $A B$, ${ }^{2}$ Department of Medicine, University of Alberta, Edmonton, AB, ${ }^{3}$ Mazan- 
kowski Heart Centre, University of Alberta, Edmonton, $A B,{ }^{4}$ Department of Cardiac Sciences, Cumming School of Medicine, University of Calgary, Calgary, AB, ${ }^{5}$ Libin Cardiovascular Institute of Alberta, Cumming School of Medicine, University of Calgary, Calgary, $\mathrm{AB},{ }^{6} \mathrm{CK}$ Hui Heart Centre, University of Alberta, Edmonton, $A B$, ${ }^{7}$ Department of Community Health Sciences, Cumming School of Medicine, University of Calgary, Calgary, AB, ${ }^{8}$ Alberta Health Services, Calgary, $\mathrm{AB},{ }^{9} \mathrm{O}$ 'Brien Institute of Public Health, Cumming School of Medicine, University of Calgary, Calgary, AB, ${ }^{10}$ Saint Luke's Mid America Heart Institute, University of Missouri-Kansas City, Kansas City, MO, USA

\section{TRAUMA INFORMED CARE: AN EVALUATION OF INTERDISCIPLINARY EDUCATION}

Claire Lothian', Lauren Campbell ${ }^{1}$, Kari McFee', Breanna Kehler ${ }^{2}$, Tamara Yee ${ }^{1}$

'Undergraduate Medical Education, Cumming School of Medicine, ${ }^{2}$ Faculty of Social Work, University of Calgary, Calgary, $A B$

\section{LOCALIZATION OF THE EPILEPTOGENIC ZONE USING INTRACRANIAL EEG-FMRI}

William Wilson ${ }^{1,2,3}$, Daniel J. Pittman ${ }^{1,2}$, Victoria Mosher ${ }^{1,2}$, Negar Mohammadi ${ }^{1,2,3}$, Joseph Peedicail ${ }^{4,5}$, Paolo Federi$\mathrm{CO}^{1-5}$

${ }^{1}$ Hotchkiss Brain Institute, University of Calgary, ${ }^{2}$ Seaman Family MR Research Centre, Calgary AB, ${ }^{3}$ Department of Neuroscience, University of Calgary, ${ }^{4}$ Department of Clinical Neurosciences, University of Calgary, ${ }^{5}$ Department of Radiology, University of Calgary, Calgary AB

\section{GLOBAL STRUCTURAL CONNECTIVITY OF THE CONTRALESIONAL HEMISPHERE IS ASSOCIATED WITH CLINICAL FUNCTION IN HEMIPARETIC CHILDREN WITH PERINATAL STROKE}

Brandon Craig ${ }^{1,2}$, Alicia Hilderley ${ }^{1,2}$, Eli Kinney-Lang ${ }^{1,2}$, Helen Carlson ${ }^{1,2}$, Adam Kirton ${ }^{1-3}$

${ }^{1}$ Calgary Pediatric Stroke Program, ${ }^{2}$ Hotchkiss Brain Institute, ${ }^{3}$ Department of Clinical Neurosciences, Pediatrics, and Radiology, University of Calgary, Calgary, AB

\section{USING A NOVEL ENHANCED NON-CONTRAST CT SCAN TO DETECT ISCHEMIA IN ACUTE STROKE PATIENTS}

Moiz Hafeez¹, Wu Qiu', Mohamed Najm¹, Hulin Quang ${ }^{1}$, Alexis T Wilson', Michael Hill', Elizabeth A Krupinski², Tolulope Sajobi', Mayank Goyal ${ }^{1,3}$, Andrew M Demchuk ${ }^{1,3}$, Bijoy K Menon ${ }^{1,3}$

'Department of Clinical Neurosciences, Cumming School of Medicine, University of Calgary, Calgary, AB, ${ }^{2}$ Depart- ments of Radiology and Imaging Sciences, Emory University, Atlanta, GA, ${ }^{3}$ Hotchkiss Brain Institute, Cumming School of Medicine, University of Calgary, Calgary, AB

FROM SWAMP TO BEDSIDE-HOPPING ACROSS THE EVOLUTIONARY HIGHWAY

Mufaddal I. Baghdadwala', Richard J. A. Wilson'

'Department of Physiology \& Pharmacology, Hotchkiss Brain Institute, University of Calgary, Calgary, AB

\section{LOCAL NETWORK PROCESSING IN CRHPVN NEURONS}

Neilen P. Rasiah ${ }^{1}$, Tamas Füzesi², David G. Rosenegger ${ }^{1}$, Leonardo A. Molina ${ }^{2}$, Jaideep S. Bains ${ }^{1}$

${ }^{1}$ Hotchkiss Brain Institute, Department of Physiology and Pharmacology, ${ }^{2}$ Cumming School of Medicine Optogenetics Core Facility, University of Calgary, Calgary, AB

INVESTIGATING THE RADIOSENSITIVITIES OF DIFFERENT NEURAL CELL TYPES

Daniel N. Berger ${ }^{1}$, Aaron A. Goodarzi', Jennifer A. Chan ${ }^{1}$

${ }^{1}$ Charbonneau Cancer Institute, University of Calgary, Calgary, AB

\section{UNDERSTANDING STROKE REHABILITATION PROGRESSION} IN A ROBOTIC REHABILITATION TRIAL

Alexa Keeling ${ }^{1,2}$, Tyler Cluff2,3, Michael D. Hill',2, Stephen Scott ${ }^{4}$, Sean P. Dukelow1,2,3

'Department of Clinical Neuroscience, University of Calgary, Calgary, $\mathrm{AB},{ }^{2}$ Hotchkiss Brain Institute, University of Calgary, Calgary, $A B,{ }^{3}$ Faculty of Kinesiology, University of Calgary, Calgary, AB, ${ }^{4}$ Department of Biomedical and Molecular Sciences, Queen's University, Kingston, ON

GABA AND GLX CHANGES IN DURING MOTOR LEARNING IN CHILDREN RECEIVING TRANSCRANIAL DIRECT CURRENT STIMULATION

Chidera Nwaroh ${ }^{1,2,3,4}$, Adrianna Giuffre ${ }^{2,3,5,6}$, Lauran Cole $^{2,3,5,6}$, Tiffany Bell ${ }^{1,2,3,4}$, Helen L Carlson ${ }^{2,3,7}$, Frank P MacMaster ${ }^{2,3,4,7,8,9}$, Adam Kirton ${ }^{2,3,6,7}$, Ashley D Harris', ${ }^{1,2,3,4}$

${ }^{1}$ Department of Radiology, University of Calgary, ${ }^{2}$ Alberta Children's Hospital, ${ }^{3}$ Hotchkiss Brain Institute, ${ }^{4}$ Child and Adolescent Imaging Research Program, ${ }^{5}$ Department of Neuroscience, University of Calgary, ${ }^{6}$ Department of Pediatrics, University of Calgary, 'Department of Psychiatry, University of Calgary, ${ }^{8}$ The Mathison Centre for Mental Health Research and Education, University of Calgary, Calgary, AB, ${ }^{9}$ Addictions and Mental Health Strategic Clinical Network 
ESTABLISHING A PEDIATRIC BRAIN COMPUTER INTERFACE PROGRAM FOR CHILDREN WITH QUADRIPLEDIA

Zeanna Jadavji ${ }^{1,2,3}$, Ephrem Zewdie ${ }^{2,4}$, Adam Kirton ${ }^{2,3,4}$

1Department of Neuroscience, ${ }^{2}$ Calgary Pediatric Stroke Program, ${ }^{3}$ Cumming School of Medicine, ${ }^{4}$ Department of Pediatrics and Clinical Neurosciences, University of Calgary, Calgary, AB

WHEN A NEUROSURGEON SHOULD CARE ABOUT PNEUMONIA: THE CASE FOR PNEUMOCYSTIS JIROVECII PNEUMONIA PROPHYLAXIS IN NEUROSURGICAL PATIENTS

Madeleine de Lotbiniere-Bassett ${ }^{1,2}$, Mannat Dhillon ${ }^{2}$, Philippe Couillard ${ }^{1,2}$, Paul J.E. Boiteau

${ }^{1}$ Department of Clinical Neurosciences, ${ }^{2}$ Cumming School of Medicine and ${ }^{3}$ Department of Critical Care Medicine, University of Calgary, Calgary, AB
SENSORIMOTOR ASSESSMENT OF CHILDREN WITH PERINATAL STROKE AND HEMIPARESIS FOLLOWING INTENSIVE MOTOR LEARNING THERAPY

Lauran Cole ${ }^{1,2,3}$, Adrianna Giuffre ${ }^{1,2}$, Megan Metzler ${ }^{1,2}$, Jacquie Hodge 2 , Jacinda Larson ${ }^{2}$, Sean Dukelow ${ }^{1,3}$, Adam Kirton $n^{1,2,3,4}$

${ }^{1}$ Department of Clinical Neuroscience, University of Calgary, ${ }^{2}$ Calgary Pediatric Stroke Program, Alberta Children's Hospital, ${ }^{3}$ Cumming School of Medicine, University of Calgary, ${ }^{4}$ Department of Pediatrics, University of Calgary, Calgary, AB 